\title{
Improved methods of testing and release of Aphidoletes aphidimyza (Diptera: Cecidomyiidae) for aphid control in glasshouses
}

\author{
JEROEN VAN SCHELT and SANDRA MULDER \\ Koppert B.V., Veilingweg 17, P.O. Box 155, 2650 AD Berkel en Rodenrijs, The Netherlands
}

\begin{abstract}
Key words. Amblyseius cucumeris, Amblyseius degenerans, predatory mites, Aphidoletes aphidimyza, gallmidge, mating, spider
\end{abstract} webs, release system, quality control, dispersal, intraguild predation, biological control

\begin{abstract}
The gallmidge Aphidoletes aphidimyza is used commercially to control aphids infesting greenhouse crops such as sweet pepper and tomato. In this study we investigated several different ways of improving its use as a biocontrol agent. In the laboratory there was a very strong relation between the availability of spider's webs and successful mating. When mated in cages containing spider's webs a greater proportion of the females were mated and the females laid more eggs compared to the females in cages without spider's webs. As adults emerging from cocoons can crawl up through $15 \mathrm{~cm}$ of vermiculite it is possible to transport and release them from bottles, which can be placed open in a greenhouse instead of having to spread the material around the plants. Dispersal of adults from the bottles was measured by placing sentinel plants around a single release point. Eggs of the gallmidge were found on plants at distances up to $45 \mathrm{~m}$ from the release point. Intraguild predation of the eggs of the gallmidge by the mites $A m b l y-$ seius degenerans and Amblyseius cucumeris was also assessed.
\end{abstract}

\section{INTRODUCTION}

The gallmidge Aphidoletes aphidimyza (Rondani) is sold by several producers of beneficial insects and used to control aphids infesting greenhouse crops. The larvae of this midge eat many species of pest aphids. For a general overview of the biology of $A$. aphidimyza see Kulp et al. (1989)

Although its potential for controlling pests is high, and it has often proved effective in the field, sometimes there are unexplained failures. In order to improve the effectiveness of the gallmidge as a biocontrol agent we studied its mating behaviour and fecundity, intraguild predation by predatory mites and release systems both in the laboratory and in commercial greenhouses.

A fecundity test method was developed by the IOBC working group "Quality control of mass-reared arthropods" (van Lenteren, 1996). After emergence gallmidges are allowed to mate in a cage for one day before placing the individual females in trays with aphid infested leaves. This method of assessing fecundity was used as part of our standard quality control procedure for two years. However, the results were very variable, which made it an unreliable quality control test. Many of the females did not lay eggs, although they survived as long as those that did. Dissection of females that did not oviposit revealed that eggs were present in their abdomens, which led to the conclusion that unsuccessful mating could be the reason for their not ovipositing.

Previously we showed that large cages $(60 \times 60 \times 60 \mathrm{~cm})$ were needed for successful mating and egg laying (van Schelt et al., 1991). Although the percentage of females laying eggs is greater in large cages, the high variability in fecundity test was puzzling.
In greenhouses midges were often observed hanging in spider's webs. This led to the hypothesis that these webs could be crucial for successful mating.

Hauser (1986) gives a drawing of mating midges, but does not mention spider's webs. Her experiments were done in wooden boxes $(10 \times 10 \times 15 \mathrm{~cm})$. She observed 7 matings, which either occurred on a leaf or on threads of cottonwool. Mean copulation time was 1.54 minutes.

Havelka (1982) mentions that the structure of the walls of the cage is important. Rough surfaces like that of wood and cotton wool are preferred. They have also been observed mating on the edges of leaves.

Sell \& Kuo-Sell (1987) recorded that between 40 and $60 \%$ of the females were fertile, but did not give an explanation for this low percentage.

Havelka \& Zemek (1999) showed that there are large differences in fecundity between females from different geographical populations. The percentage of sterile females differed between populations, but became less variable after they were reared for at least ten generations in the laboratory.

In this study the effect of spider's webs on mating success and fecundity was investigated in experiments one and two.

Most sweet pepper growers use the mite Amblyseius degenerans (Berlese) as well as Amblyseius cucumeris (Oudemans) for controlling thrips. It is known that $A$. degenerans is very polyphagous. We tested the hypothesis that this mite influences the effectiveness of $A$. aphidimyza by eating its eggs.

The mite A. cucumeris is widely used to control thrips infesting sweet pepper (van Driesche et al., 1998). Although this mite is known to be less polyphagous than A. degenerans (van Houten et al., 1995), its role as a 
potential predator of the eggs of $A$. aphidimyza was also studied.

Another factor that might affect the effectiveness of $A$. aphidimyza is the way it is commercially distributed. Until now, the recommendation was to place small heaps of vermiculite (carrier material) mixed with cocoons on rockwool at the base of each plant across from the irrigation dripper. Even though the cocoons are placed on moist rockwool, those close the surface can dry out, which has an adverse effect on the emergence of the midges.

Another negative effect is predation of the unprotected cocoons by ants and mice.

Probably it is not necessary to carefully distribute cocoons within a greenhouse because once the midges emerge they can locate aphid colonies from a distance. Therefore, the proportion of midges that successfully emerge from standard packing bottles was determined. In these bottles the cocoons are protected and kept at the right humidity. Because $A$. aphidimyza normally pupates in soil it should be adapted to find its way to the surface after emergence. Uygun (1971) found 94\% of the cocoons in the first $1 \mathrm{~cm}$ and the remaining $6 \%$ were not deeper in the soil than $3 \mathrm{~cm}$. The ability of midges to emerge from below $15 \mathrm{~cm}$ of vermiculite was determined in experiment five.

The change in the method of introducing midges into greenhouses (whole bottles vs. small heaps) was accompanied by a reduction in the number of release points within a greenhouse. Recommended release rates vary from 1-10 cocoons $\mathrm{m}^{2}$, which means that midges need to be able to disperse at least 30 meters from bottles containing 1000 cocoons. The distance adult midges can disperse was tested indirectly in a cucumber crop within a greenhouse using sentinel plants.

\section{MATERIAL AND METHODS}

\section{First experiment: Mating of $A$. aphidimyza on natural spi- der's webs}

Two muslin cages of $60 \times 60 \times 60 \mathrm{~cm}$ were prepared for emergence and mating. One cage was carefully cleaned whereas several spider's webs (without spiders) were left in the other cage. A small pot of barley infested with Rhopalosiphum padi (L.) was placed in each cage as an egg-laying stimulant and as a source of honeydew for food (Gilkeson, 1987). An average of 150 cocoons in moist vermiculite was put in each cage. The cages were kept at $23^{\circ} \mathrm{C}$, and a photoperiod of $16 \mathrm{~L}: 8 \mathrm{D}$. The morning after the midges emerged the temperature in the cages was reduced to $6^{\circ} \mathrm{C}$ for $15 \mathrm{~min}$. to inhibit flying. Female midges were then collected and placed individually in ventilated trays containing agar on which rested cucumber leaf discs infested with Aphis gossypii (Glover). To facilitate ventilation the trays ( 25 for each treatment) were inverted over gauze. The temperature was kept at $23^{\circ} \mathrm{C}$, and after four days the percentage of fertile midges and the number of eggs per midge were assessed.

Second experiment: Mating of $A$. aphidimyza on collected spider's webs

To standardize the size of the webs, some were collected with a metal ring $(\varnothing 15 \mathrm{~cm})$. In one cage two rings with spider's webs were placed: one vertically and one horizontally orientated. The other cage lacked webs. Further procedure was as in experiment 1 .

\section{Third experiment: Intraguild predation by Amblyseius degenerans}

This was done in a greenhouse in two $3 \mathrm{~m}^{2}$ cages. The temperature was kept at $22^{\circ} \mathrm{C}$ during the day and $20^{\circ} \mathrm{C}$ during the night. Twelve sweet pepper plants (height $60 \mathrm{~cm}$ ) infested with the tobacco aphid, Myzus persicae nicotianae (Blackman), were placed in each cage. The aphid populations were allowed to increase for one week. In one cage, A. degenerans mites were introduced from the start and a small amount of pollen (Typha sp.) was supplied as a food source, so that they increased in abundance. About 400 cocoons of $A$. aphidimyza were placed in both cages. When the midges emerged, an average of 50 aphids and 4-8 mites were present on each leaf. Three days after the emergence of the midges, 20 leaves were selected at random from both cages. The number of healthy eggs and eggs eaten by mites was assessed. Six days later, another 20 leaves were selected and the number of gallmidge larvae on each leaf counted.

\section{Fourth experiment: Intraguild predation by Amblyseius cucumeris}

The same procedure was followed as in the previous experiment, but the mites were released directly onto the leaves one day after the first gallmidge eggs were found. A. cucumeris was released in a mixture of prey and predator mites (ratio of Tyrophagus putrescentiae (Schrank): A. cucumeris < 1) in vermiculite.

One and five days later the number of eggs eaten by mites and the number of midge larvae were counted. At the second census the number of aphids per leaf was also assessed.

\section{Fifth experiment: Emergence of $\boldsymbol{A}$. aphidimyza from bottles}

Three $500 \mathrm{cc}$. polypropylene bottles each containing 1000 cocoons in moist ( $5 \%$ water by volume) fine vermiculite were placed in a cage at $24^{\circ} \mathrm{C}$. until all midges had emerged. The cocoons from three depths $(0-5,5-10,10-15 \mathrm{~cm})$ in the bottles were checked for emergence. The vermiculite was also checked for the presence of adult midges.

Sixth experiment: The dispersal of $A$. aphidimyza in a greenhouse

The long-range flight test was carried out in a commercial cucumber greenhouse (length $300 \mathrm{~m}$, width $100 \mathrm{~m}$ ). The greenhouse contained an aphid free $2.5 \mathrm{~m}$ tall cucumber crop growing on rockwool. Approximately 1000 cocoons (3.4 grams) were placed in a Petri dish surrounded by a water barrier in the centre of the greenhouse. Two pots containing wheat seedlings infested with $R$. padi were placed at every 3 meters, along four 45 meter axes radiating out along compass directions from the centre of the greenhouse. Two days after emergence of the midges, the pots were collected and kept individually a further 6 days after which they were checked for the presence of gallmidge larvae.

\section{RESULTS AND CONCLUSIONS}

First and second experiment: Mating of $A$. aphidimyza on natural and collected spider's webs

In the morning following emergence, midges were observed mating on the spider's webs. Males and females were hanging by their front legs from the threads of the webs and copulating face to face (Hauser, 1986).

Counting the number of eggs in the trays after four days, revealed that the number of fertile midges, as well 
as the number of eggs per midge was higher in the cage with spider's webs than in the clean cage (Table 1).

TABLE 1. Percentage of fertile females and number of eggs laid by $A$. aphidimyza. Emergence in a cage with natural spiders webs vs. a clean cage. (Numbers in the same column followed by a different letter are statistically different. Fertility: Chisquare, $\mathrm{P}<0.05$, number of eggs: Wilcoxon, $\mathrm{P}<0.05$ )

\begin{tabular}{cccc}
\hline \multicolumn{1}{c}{ treatment } & $\mathrm{n}$ & $\%$ fertile & Number of eggs/fert. fem. \\
\hline + natural web & 25 & $88 \%^{\mathrm{a}}$ & $70^{\mathrm{a}}(\mathrm{n}=22)$ \\
- web & 25 & $52 \%^{\mathrm{b}}$ & $51^{\mathrm{b}}(\mathrm{n}=13)$ \\
\hline
\end{tabular}

In the second experiment, all the midges were observed mating on the web held horizontally. The vertical web was not used for mating. The percentage of fertile females and number of eggs per fertile female was significantly higher in the cage with webs than in the clean cage, which confirmed the results of the first experiment (Table 2).

TABLE 2. Percentage of fertile females and number of eggs laid by $A$. aphidimyza. Emergence in a cage with a spiders web in a metal ring vs. a clean cage. (Numbers in the same column followed by a different letter are statistically different. Fertility: Chi-square, $\mathrm{P}<0.05$, number of eggs: Wilcoxon, $\mathrm{P}<0.05$ )

\begin{tabular}{cccc}
\hline treatment & $\mathrm{N}$ & $\%$ fertile & Number of eggs/fert. fem. \\
\hline + web in ring & 24 & $83 \%^{\mathrm{a}}$ & $62^{\mathrm{a}}(\mathrm{n}=20)$ \\
- web & 25 & $40 \%^{\mathrm{b}}$ & $43^{\mathrm{b}}(\mathrm{n}=10)$ \\
\hline
\end{tabular}

It was concluded that the presence of spider's webs is crucial for successful mating of $A$. aphidimyza. The "quality" of the mating also increased, because the number of eggs per mated female was significantly higher.

That is, the reliability of the laboratory quality control test can be increased by placing in each cage spider's webs held horizontally in metal rings. Therefore, we recommend that this modification of the IOBC quality control test be adopted.

\section{Third experiment: Intraguild predation by Amblyseius degenerans}

In the cages where mites were present, around $40 \%$ of the midge's eggs were eaten, versus none in the other cage (Fig. 1). Such eggs were shrivelled and easily distin-

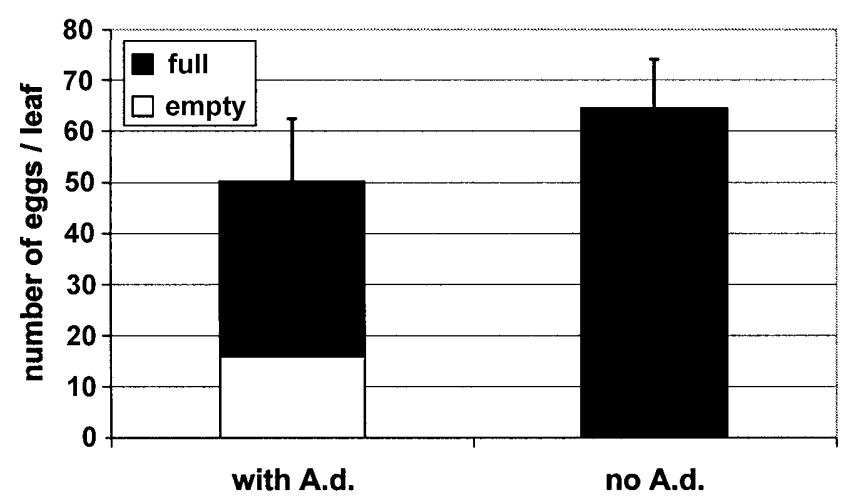

Fig. 1. The number of full and empty (eaten) eggs of $A$. aphidimyza ( + s.e.) after three days in a cage infested with $A$. degenerans, and another without $A$. degenerans.

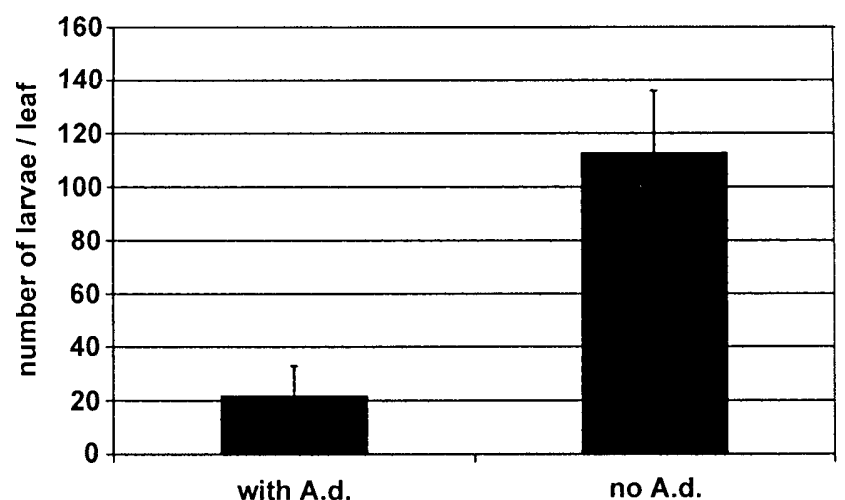

Fig. 2. The number of larvae (+ s.e.) of $A$. aphidimyza after nine days in a cage infested with $A$. degenerans, and another without $A$. degenerans.

guished from intact eggs. Most mites were an orangeblack colour instead of the normal brown-black, due to eating on the orange eggs off the gallmidge.

The difference in the number of gallmidge larvae (after 6 days) was even greater; 21 on the plants with mites, vs. 112 on the plants without ( $<<0.05$, K.W.) (Fig. 2). Mites were not observed attacking small larvae, but it cannot be excluded.

\section{Fourth experiment: Intraguild predation by Amblyseius cucumeris}

In the cage with $A$. cucumeris $23 \%$ of the eggs were eaten after one day versus $1.3 \%$ in the cage without predatory mites (Fig. 3). On average there were 23 mites

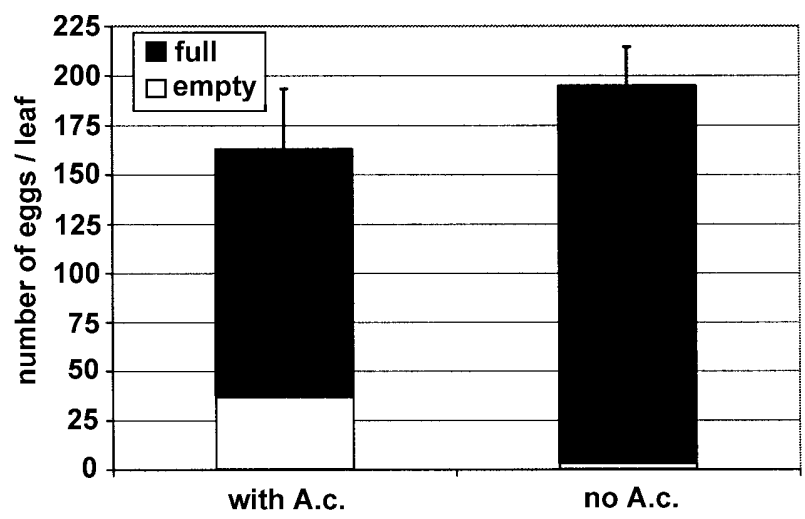

Fig. 3. The number of full and empty (eaten) eggs (+ s.e.) of $A$. aphidimyza in a cage infested with $A$. cucumeris, and another without $A$. cucumeris.

per leaf vs. 0.4 in the control treatment. The total number of gallmidge eggs per leaf was 162 in the mite cage vs. 195 in the control treatment.

After five days the number of larvae per leaf was in each cage 15 but there were no aphids in the cage without mites and 130 in the cage with mites. Probably most of the larvae in the cage without mites dispersed when the aphids became scarce (Fig. 4). 


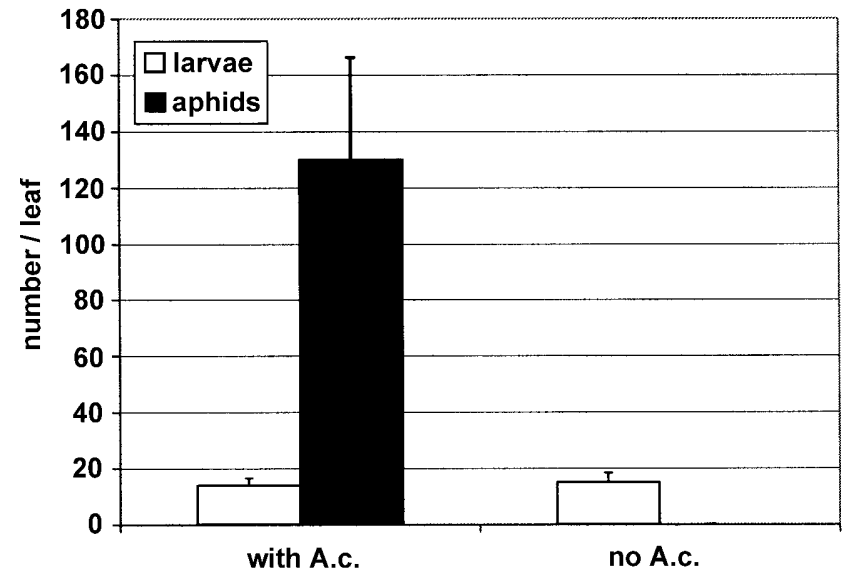

Fig. 4. The number of larvae ( + s.e.) of $A$. aphidimyza and aphids (Myzus persicae nicotianae) $(+$ s.e.) in a cage infested with $A$. cucumeris, and another without $A$. cucumeris.

\section{Fifth experiment: Emergence of $\boldsymbol{A}$. aphidimyza from the bottles}

At all three depths within the bottles the cocoons were found empty $(100 \%$ emergence, $\mathrm{n}=50)$ and normally eclosed. No adult midges were found in the vermiculite. We observed that after leaving their cocoons midges, push themselves through the vermiculite while still in their pupal exuviae. Most of the empty pupal exuviae were found attached around the neck of a bottle or on top of the vermiculite, where the final emergence had taken place.

Simply placing an open bottle containing cocoons of $A$. aphidimyza in a greenhouse has now become the standard means of releasing this midge.

\section{Sixth experiment: The dispersal of $A$. aphidimyza in greenhouses}

The midge showed no preference for a particular compass direction, and the number of pots of plants infested with aphids attacked by midge larvae within and between rows was the same. Therefore the results for each distance along the four compass directions were pooled. (Fig. 5). At a distance of $36 \mathrm{~m}, 70 \%$ of the pots were found by midges. Thus, the use of bottles with cocoons is an effective means of releasing midges in greenhouses, even at the lowest introduction rate of $1 \operatorname{cocoon} / \mathrm{m}^{2}$.

\section{GENERAL DISCUSSION}

The importance of spider's webs for mating in $A$. aphidimyza was shown for the first time. By making spider's webs available to midges it was possible to greatly improve the standard laboratory fecundity testing procedure. Implications of this for use of midges in the field will be investigated further. Spider's webs could be a limiting factor, especially with a new planting when the grower puts new plastic on the ground and cleans the greenhouse with chemicals. Preliminary trials however, showed that spider's webs are ubiquitous and midges are very good at finding them.

Intraguild predation of $A$. aphidimyza eggs by the mites $A$. degenerans and $A$. cucumeris was demonstrated. In our

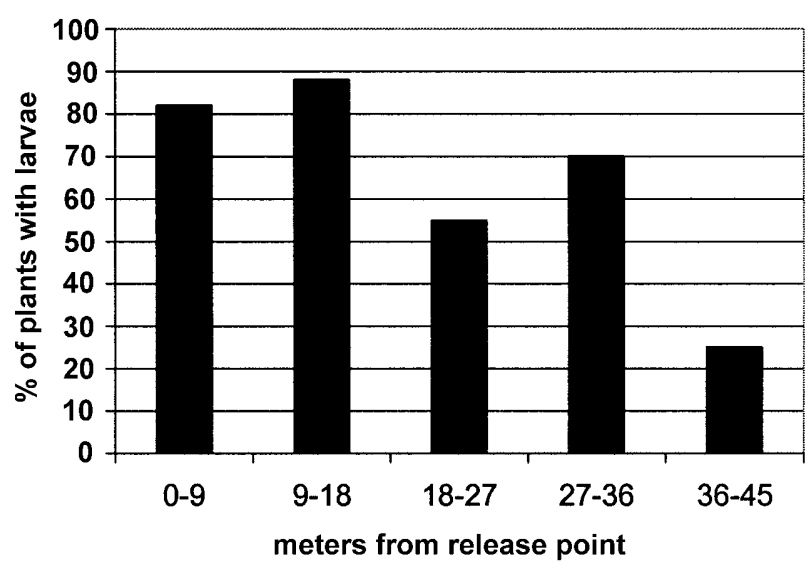

Fig. 5. The percentage of plants (winterwheat and $R$. padi) with larvae of $A$. aphidimyza. The percentages are based on 24 plants at each distance. A. aphidimyza was released from a central point in a cucumber greenhouse.

trials the numbers of mites and gallmidge eggs per leaf were relatively high compared to greenhouse situations. In practice the advantages of using $A$. degenerans and $A$. cucumeris to control thrips on sweet pepper should be weighed against the possible disruption of the aphid control by $A$. aphidimyza. It is likely that more predators (mirids, anthocorids, coccinellids etc.) will prey on the soft and vulnerable stages of the midge. Brødsgaard \& Enkegaard (1997) found that Orius majusculus (Reuter) is a predator of $A$. aphidimyza larvae.

The successful emergence of midges from cocoons buried as deep as $15 \mathrm{~cm}$ in vermiculite and the ability of adult midges to find aphid colonies at a distance of 35 meters has resulted in the development of a simpler release method. Growers now place open bottles of cocoons at the beginning of a row instead of establishing several release points along each row of a crop. It is estimated that this saves the grower half an hour/ha.

\section{REFERENCES}

BrøDSGAARD H.F. \& ENKEgAaRd A. 1997: Interactions among polyphagous anthocorid bugs used for thrips control and other beneficials in multi-species biological pest management systems. In Pandalai S.G. (ed.): Recent Research Development in Entomology. Research Signpost, Trivandrum, pp. 153-160.

Driesche R.G. van, Heinz K.M, Lenteren J.C. van, LoOMANS A., Wick R., Smith T., Lopes P., SANderson J.P., Daughtrey M. \& Brownbridge M. 1998: Western Flower Thrips in Greenhouses: a Review of its Biological Control and Other Methods. Floral Facts, Univ. of Mass., 31 pp.

GILKESON L.A. 1987: A note on fecundity of the aphid predator, Aphidoletes aphidimyza (Rondani) (Diptera: Cecidomyiidae). Can. Entomol. 12: 1145-1146.

HAUSER I. 1986: Untersuchungen zu Verhalten und Lebensweise der räuberischen Gallmücke Aphidoletes aphidimyza (Rond.) (Diptera: Cecidomyiidae). Dissertation Göttingen, Göttingen, $124 \mathrm{pp}$.

Havelka J. 1982: Predatory gallmidge Aphidoletes aphidimyza (R.) - method of mass rearing and use for biological control in the greenhouse. Proc. IOBC East Palearctic Regional Section "Methods of Integrated Pest Management", Poznan, Poland, pp. 89-121 (in Russian). 
Havelka J. \& ZeMEK R. 1999: Life table parameters and oviposition dynamics of various populations of the predacious gallmidge Aphidoletes aphidimyza. Entomol. Exp. Appl. 91: 481-484.

Houten Y.M. van, Rum P.C.J. van, Tanigosmi L.K., Stratum P. VAN \& BRUIN J. 1995: Preselection of predatory mites to improve year-round biological control of western flower thrips in greenhouse crops. Entomol. Exp. Appl. 74: 225-234

Kulp D., Fortmann M., Hommes M. \& Plate H.-P. 1989: Die räuberische Gallmücke Aphidoletes aphidimyza (R.) (Dipt: Cec.). Ein bedeutender Blattlausprädator: Nachschlagewerk zur Systematik, Verbreitung, Biologie, Zucht und Anwendung. Mitt. Biol. BundAnst. Land- u. Forstw. 250: 126 pp.
Lenteren J.C. van 1996: Quality control tests for natural enemies used in greenhouse biological control. Bull. IOBC/WPRS 19: 83-86.

Schelt J. van, Douma J.B. \& Ravensberg W.J. 1991: A quality control test for the predatory midge Aphidoletes aphidimyza. Workshop IOBC global working group 5 "Quality Control of Mass Reared Arthropods". Wageningen, pp. 90-94.

Sell P. \& Kuo-Sell H.L. 1987: Leistüngsfähigkeit der aphidophagen Gallmücke Aphidoletes aphidimyza (Rondani) (Dipt.: Cecidomyiidae) in Abhängigkeit von verscheidenen Einflussfaktoren. J. Appl. Entomol. 103: 434-447.

Uygun N. 1971: Der Einfluss der Nahrungsmenge auf Fruchtbarkeit und Lebensdauer von Aphidoletes aphidimyza. $Z$. Angew. Entomol. 69: 234-258

Received January 6, 2000; accepted July 15, 2000 